\title{
A 'SURE' Approach to Testing for Convergence in Regional Integrated areas: An Application to Output Convergence in Mercosur
}

\author{
Mariam Camarero \\ Jaume I University \\ Renato G. Flôres \\ Fundaçao Getulio Vargas \\ Cecilio Tamarit \\ University of Valencia
}

\begin{abstract}
In this paper we propose the use of a sequential multivariate approach to test for convergence. These tests allow us to reconcile the time series literature with the cross-sectional dimension which is basic when testing for convergence in regional blocs. In addition, this methodology helps to avoid the problem due to the limited dataset length. We apply multivariate unit root tests in two stages. First, we test for non-convergence without identifying the countries within the group that effectively converge and, in a second stage, the countries that converge are identified. The SURE technique allows for the existence of correlations across the series without imposing a common speed of mean reversion. The empirical results for Mercosur countries show that there is evidence of catching up of the small countries towards
\end{abstract}

\footnotetext{
*Corresponding address: Cecilio Tamarit, Department of Applied Economics II, University of Valencia, PO Box 22006, E-46071 Valencia (Spain). Phone: +34963828349; Fax: +34963828354, E-mail: Cecilio.Tamarit@uv.es, Mariam Camarero, Economics Department, Jaume I University. Campus de Riu Sec, E-12071 Castell ón (Spain). Phone: +34964728595, Fax: +34964728591, E-mail: camarero@eco.uji.es. Renato G. Flôres Jr., EPGE/Fundaçao Getulio Vargas, Praia de Botafogo, 190 Sala 1100, RIO DE JANEIRO, RJ, 22250900, Brazil, Phone: 2259-5909, Fax: 2553-8821 
Brazil and, to some extent, Argentina. In contrast, the evidence of catching-up among the larger countries is weaker.

- JEL classification: F15, C22, C15

- Keywords: Convergence, Trade liberalization, Multivariate tests, Unit roots, Mercosur, Per capita income, SURE

\section{Introduction}

The purpose of this paper is to study per capita income convergence among South-American countries, notably Mercosur members and associates. The studies on economic convergence have usually focused on developed countries, and more precisely on OECD economies. However, real convergence, that is, the tendency of per capita income of different economies to equalize over time, as predicted by Solow's (1956) neoclassical growth model, remains a vital and controversial question for developing countries. Recent studies have illustrated that standard trade theories provide no clear prediction as to the impact of trade liberalisation on output convergence ${ }^{1}$. This is particularly true for countries that are experiencing a process of economic integration, either at a multilateral or at a regional level.

Conventional neoclassical theory predicts that regional disparities within a country should disappear in the long run by trade and factor mobility. Therefore, in an extension of this argument to inter-country regional disparities, economic integration, which increases trade and factor mobility, should lead to a more efficient allocation of resources and hence to a narrower gap between poor and rich regions. In contrast to the regional convergence theory, the "new economic geography" theory argues just the opposite, that economic integration exacerbates regional divergence. The reason for this is that economic integration creates new opportunities for economies of scale and specialization which tend to encourage greater spatial agglomeration and localization in regional activity. According to the agglomeration theory of Krugman (1991) and to the endogenous growth model of Romer (1986) production factors will be concentrated in the more developed regions as a result of increasing returns to scale and externalities. The final effect remains an open empirical question.

Moreover, from a methodological point of view, as empirical applications deal with groups of countries, it is somewhat surprising that empirical tests resorting to

${ }^{1}$ See , for instance, Ben-David (1996) or Slaughter (2001). 
a multivariate treatment of the problem are scarcely used. In fact, the importance of a multivariate approach was already stressed in Baumol (1994), who described specific contagion mechanisms at work.

In order to overcome this problem, we apply in this paper recently proposed multivariate tests, that reconcile the importance of the cross-sectional dimension for the assessment of convergence with the well established inference procedures coming from the time series literature. By adding the cross-section dimension we increase the amount of information for each time period, and therefore, we solve the problem due to the lack of power in unit root tests when the root is close to one, especially in small samples (Shiller and Perron, 1985). Moreover, using short samples with rich information helps us to avoid a second serious problem arising from the fact that standard unit root tests are biased towards the non-rejection of the null hypothesis (of non convergence) in the presence of structural breaks. Obviously, as we reduce the sample length, the probability of discontinuities in the series generated either by shocks or institutional changes diminishes.

Finally, as pointed out by Cheung and García-Pascual (2004), under a standard panel unit root setting, the rejection of the null hypothesis is commonly interpreted as the rejection of the joint hypothesis for all the possible differential series. However, convergence may only appear for a subset of countries that are not identified by the test.

In this paper we apply several tests that help to overcome the previous problems. Starting with the pooled test first used by Abuaf and Jorion (1990), multivariate tests have been derived that allow for different degrees of heterogeneity in the cross-sections, with the important property of exploiting the information in the covariances among the group of countries. Examples are the tests proposed by Flôres et al. (1999), Sarno and Taylor (1998) and Breuer et al. (2002).

We contribute to previous empirical literature on convergence by proposing here an econometric methodology that comprises a range of techniques. To sum up, we control for the following issues neglected in previous literature: first, we account for cross-section dependence among countries on the panel tests. Second, the gist of our approach is the sequential application of the above mentioned multivariate tests. We overcome the identification problem derived from the joint-hypothesis nature of panel time-series tests, that is, that even if we reject the joint hypothesis of convergence, it may only take convergence in a subset of countries, which are not identified. Here, following the two step procedure included in our proposal, a robust identification of convergence clubs is achieved. Third, we use sample- 
specific critical values calculated by bootstrap techniques which improve the tests performance in finite samples.

We apply this methodology to the case of Mercosur. In 1991 the signature of the Treaty of Asunción initiated the creation of a common market on a South-South basis. The governments of the countries involved hoped that the creation of this economic integrated area would contribute to a higher economic growth and income convergence between partners. However, the effect of economic integration and trade liberalisation in Latin America remains controversial. According to different studies like Bowman and Felipe (2001), Caceres and Sandoval or Dobson and Ramlogan (2002) there has been a stable trend in the process of convergence in the 1970-1992 period. Actually, the Southern Cone has been the only region to exhibit beta-convergence and sigma-convergence both in per worker and per capita income in the 1960-1990 period. However, the launching of the Mercosur initiative created new expectations about disparities that could be endogenously generated by the integration process and, therefore, governments have been paying more attention to the empirical evidence in order to smoothen the transition. According to Volpe Martincus (2000), the removal of bilateral trade barriers between Argentina and Brazil has increased intra-industry trade changing trade specialization patterns and the spatial location of industries. Moreover, according to Serra et al. (2006), trade liberalization has temporarily increased national output per capita disparities among middle income Latin American countries. All in all, the global effect on income convergence remains an open empirical question.

The paper is organized as follows. Section 2 surveys the several ways of measuring convergence, as well as the notion of convergence itself. Section 3 briefly discusses the testing methods used in the paper within the framework of our proposal. Section 4 presents the empirical results using the methodology proposed and, finally, section 5 concludes.

\section{Methodological Approaches to the Measurement of Convergence: a Synthesis}

The definition of convergence has been changing over time as a result of a feedback process between theory and empirics ${ }^{2}$. In this large and abundant literature, two main approaches can be highlighted: the first one is based on cross-section

$\overline{{ }^{2} \text { For a survey on alternative }}$ concepts of convergence, see Baumol, Nelson and Wolff (1994). 
data, whereas the second one relies on time series information and econometric procedures.

The first approach, summarized in the upper panel of Table 1, relies on the traditional definition of convergence in the cross-section literature that is associated with Sala-i-Martin (1990). He defined two concepts of convergence derived from the classical growth literature: $\beta$-convergence and $\sigma$-convergence. There is $\beta$ convergence if poor economies tend to grow faster than the rich ones. In this case, per capita incomes of countries converge to one another in the long-run, independently of their initial conditions.

A group of economies is $\sigma$-converging if the dispersion of their real per capita GDP levels tends to decrease over time.

Both concepts are related, so that a necessary condition for the existence of $\sigma$ convergence is the existence of $\beta$-convergence (Sala-i-Martin, 1996).

In the eighties, Baumol (1986), using Maddison's data-set, consisting of 13 rich

Table 1. Summary of definitions and empirical results in testing for output convergence

\begin{tabular}{ll}
\hline \multicolumn{1}{c}{ Empirical approach I : cross-section } \\
\hline \multicolumn{1}{c}{ Definitions } & \multicolumn{1}{c}{ Main evidence } \\
Sala-i-Martín (1990): $\alpha$ and & - Baumol (1986): convergence. Ex-post sample selection \\
$\beta$-convergence & bias \\
& - Summer and Heston (1991): divergence. Larger group. \\
& - Mankiw, Romer and Weil (1992): conditional convergence
\end{tabular}

Quah (1996): Convergence clubs Distributional stochastic properties of the clubs of countries

\begin{tabular}{lc}
\hline \multicolumn{1}{c}{ Empirical approach II : time series } \\
\hline $\begin{array}{l}\text { Bernard and Durlauf (1995) } \\
\text { Long-run convergence } \\
\text { (univariate) }\end{array}$ & Divergence. Too strict definition. \\
$\begin{array}{l}\text { Oxley and Greasley (1995) } \\
\text { Catching-up }\end{array}$ & Convergence using a weaker definition \\
$\begin{array}{l}\text { Reichling (1999) } \\
\text { Relative convergence }\end{array}$ & Identify clustering convergence clubs \\
\hline \multicolumn{1}{c}{ Empirical approach III : panel and multivariate non-stationarity tests } \\
\hline \multicolumn{1}{c}{ Definitions } & Main evidence \\
Bernard and Durlauf (1995) & Cheung and García-Pascual (2004) \\
\hline
\end{tabular}


countries starting in 1870 , found cross-country convergence, specially after World War II. However, Romer (1986) and Delong (1988) challenged this hypothesis of cross-country convergence, based on the problem of ex-post sample selection bias.

In order to avoid this problem, Summers and Heston (1991) used a data set that included a larger group of countries and found evidence of divergence.

However, Barro (1991) and Mankiw, Romer, and Weil (1992) found that convergence can be achieved among economies that exhibit similar characteristics and when human capital variables such as education and savings rates are controlled for (conditional convergence).

Quah (1996b) argued that the conventional analyses using cross-section data do not allow for the distinction between economic progress (that is growth both in rich and poor countries) and the relative performance or catching-up between rich and poor economies, that he calls convergence. He proposed a new approach to the empirical research in this area, that models directly the dynamics of the crosssection distribution of countries (convergence-club hypothesis). He obtained evidence on the formation of convergence clubs and on the cross section distribution polarizing into twin peaks of rich and poor.

A second approach to the analysis of convergence, as shown in Table 1, has been based on the long-run output movements in the context of time series techniques.

Bernard and Durlauf (1995) define long-run convergence between countries $i$ and $j$ if the long-term forecasts of the considered variable for both countries at fixed time $t$ are equal :

$$
\lim _{k \rightarrow \infty} E\left(y_{i, t+k}-y_{j, t+k} \mid I_{t}\right)=0
$$

where stands for the information available at time $t$. This definition will be satisfied if $y_{i, t+k}-y_{j, t+k}$ is a mean zero stationary process. It implies that for countries $i$ and $j$ to converge the two series must be cointegrated with a cointegrating vector $[1,-1]$. In addition, if the variables are trend-stationary, then the definitions imply that the time trends for each country must be the same.

The definition in equation (1) can be extended to more than two countries (multivariate convergence). In order to test for convergence, these authors use multivariate cointegration techniques with mixed results. Testing for cointegration is a powerful way of assessing whether convergence has already occurred but not if it is an on-going process. 
In order to solve this problem, Bernard and Durlauf (1995, 1996), Oxley and Greasley (1995) and Greasley and Oxley (1997) have also proposed different definitions or degrees of convergence (convergence, catching-up and common trends), that allow for a more flexible interpretation of the concept, yielding to an appropriate testing framework based on cointegration techniques. According to these authors the definition of convergence given above would correspond to the concept of long-run convergence. However, it could be the case that both series are not equal in the long-term, but proportional. That is, they may still respond to the same long-run driving processes and face the same permanent shocks with different long-run weights or different magnitude across countries. In this case the series would be cointegrated but the cointegrating vector would be $[1, \alpha]$ with $\alpha$ being $<0$ and both series would show a common trend.

Finally, if both series are cointegrated and the cointegrating vector is $[1,-1]$, but the difference between the two series is a stochastic variable with a non-zero time trend, this will show that the deviation between the series is expected to decrease but not to disappear. This case is called catching-up by Bernard and Durlauf (1995, 1996) and Oxley and Greasley (1995) ${ }^{3}$.

\section{A New Methodological Proposal: Using Multivariate unit Root Tests in a Sequential Approach}

Although the time series literature and, more specifically, the cointegration techniques, offer a well developed framework for testing for convergence, the evidence obtained has not been supportive. An attempt to overcome this apparent inconsistency has been made by Reichlin (1999) trying to combine the convergence club approach (cross-section information) to the cointegration approach (time series information). She argues that the notion of convergence derived from Quah's approach is closely related to that implied by cointegration. The difference is that while Quah cares about groups of countries, in the cointegration framework the stress is on individuals.

Reichlin (1999) proposes to make use of the cointegration framework to detect convergence clubs by looking at cointegration clusters ${ }^{4}$. Moreover, the cointegration literature has recently benefited from new developments in the area

${ }^{3}$ These definitions have been extended recently using concepts derived from fractional integration as well as non-linear unit root tests. Although these tests can be included in the time series approach, we have not considered them in this section for the sake of simplicity. 
of multivariate time series and panel tests. Although Bernard and Durlauf (1995) defined convergence in a multivariate setting, they were aware of the additional difficulties of this type of analysis, mainly related to identification (Cheung and García-Pascual, 2004). The study of convergence among a group of countries can now be analyzed using new multivariate tests. Two approaches should be outlined: first, the panel unit root and stationariy tests and, second, the multivariate unit root tests.

Levin et al. (2002) and Im, Pesaran and Shin (2003) proposed different versions of unit root tests in a panel setting, whereas Hadri (2000) built stationarity tests in panels. Although all these tests are being extensively used in the empirical literature, their main drawback is the assumption (common to all these tests) of absence of correlation across the cross-sections of the panel. That is, the individual members of the panel (countries) are independent. This assumption is not realistic and, therefore, cannot be maintained in the majority of the cases ${ }^{5}$, especially when the countries analyzed are neighbours or are involved in integration processes.

The multivariate unit root tests, in contrast, do not impose this assumption and incorporate the error covariance matrix in the estimation, by resorting to the more efficient SURE technique.

In this paper we test for Bernard and Durlauf (1995) definition of convergence sequentially. We apply different versions of multivariate unit root tests that permit, first, to analyze if there is any evidence of convergence (Sarno and Taylor (1998) and the first stage of Flôres et al. (1999) test) and, if this is the case, to identify which countries are effectively converging (second stage of Flôres et al. (1999) and Breuer et al. (2002)). The methodological approach that we adopt to test for convergence combines the advantages of the cross-section information provided by the SURE analysis of country groups accounting for their cross-dependency with the clear conditions given by the cointegration theory. In addition, we allow for

\footnotetext{
${ }^{4}$ Among a group of countries, one can find, for example, two separate groups each one cointegrated within its own members, but the two groups not cointegrated amongst them. If one conditions each group with respect to its own mean, we get a set of stationary variables, and each set is a convergence club. Thus, most of the empirical questions of cross-sectional distribution dynamics can also be answered within a time series framework for which we have well developed inference analysis.

${ }^{5}$ Some authors have proposed different alternatives in order to relax the independence hypothesis. O'Connell (1998) and Levin, Lin and Chu (2002) suggest subtracting the cross-section mean from the data. The main drawback of this approach is that it assumes that the effect of cross-section dependence is the same for all individuals. In order to account for more general situations Maddala and Wu (1999) compute the bootstrap distribution of the tests.
} 
non-zero means in the stochastic processes, so that the definition of convergence we are testing for is what can be called catching-up ${ }^{6}$ or relative convergence. A brief description of the methodology and tests follows.

\section{A. Flôres et al. (1999) multivariate unit root test.}

Flôres et al. (1999) developed multivariate testing procedures, FPS hereafter, that generalize the multivariate pooled test by Abuaf and Jorion (1990). They consider that those tests that impose the same autoregressive parameter $\rho$ for all countries do not allow to differentiate the order of integration across them. Moreover, even from an econometric point of view, it might not be necessary to impose a common $\rho$ to benefit from panel data. Thus, they propose multivariate tests with different speeds of mean reversion in the autoregressive process:

$$
d y_{i t}=\mu_{i}+\rho_{i} d y_{i t-1}+\mu_{i t}, i=1, \ldots, N
$$

They designed a testing strategy based on sequentially using a test that imposes the same autoregressive parameters. Should a rejection of the null occurs, it would indicate that at least some of the series may be stationary. Then, they suggest continuing the sequence again with their test. The rationale is that unit root tests for a particular series are more powerful if performed jointly with stationary series, because they help in weakening the influence of the non-stationary ones.

The sequential testing strategy is described below, where the Monte Carlo technique is applied in order to obtain the critical values by simulation, which ensures proper inferences:

First, under the first null hypothesis, the data generating process is based on the autoregressive model with $\rho_{i}=1$ for the $N$ countries. If the null is not rejected the sequence stops.

Second, if the null is rejected, we estimate the parameters $\rho_{i}$ and define a set of countries $I_{l}$ for which the null is rejected. We consider that these countries' series are stationary.

Finally, in a third step, a new data generating process for the null is assumed, in

\footnotetext{
${ }^{6}$ Note that the definition of convergence tested for in this paper is not the absolute but the relative one (or catching-up). Therefore, we will use hereafter both terms (convergence and catching-up) interchangeably.
} 
which the series $j \notin I_{l}$ have as slope parameters $\rho_{i}=1$, while the slope coefficients are taken at their previous point estimates, $\rho_{i}=\hat{\rho}_{j}$ for the series considered stationary, that is, $j \in I_{l}$. Then, we use the second FPS test to check whether any of the $j \notin I_{l}$ are non-stationary.

A similar testing strategy can be applied by combining two tests, proposed by Sarno and Taylor (1998) and Breuer et al. (2002), which are equivalent to an augmented version of the FPS test.

\section{B. Sarno and Taylor (1998) multivariate augmented Dickey-Fuller test $(\text { MADF })^{7}$}

Sarno and Taylor (1998) proposed a Multivariate ADF test, where the sum of the autoregressive coefficients may vary across countries under the alternative hypothesis ${ }^{8}$.

To apply the $M A D F$ test, they consider an $\mathrm{N}$-dimensional stochastic process defined by:

$$
d y_{i t}=\mu_{i}+\sum_{j=1}^{k} \rho_{i j} d y_{i t-j}+u_{i t}
$$

for $i=1, \ldots, N$, where $N$ denotes the number of series in the panel. The disturbances $\mathbf{u}_{t}=\left(u_{1} \ldots u_{N t}\right)^{\prime}$ are assumed to be independently, normally distributed, with zero means. In contrast to the standard $A D F$ test, that involves separately testing each of the N nulls of non-stationarity, Sarno and Taylor (1998) estimate the system (3) by the SURE method, taking into account the contemporaneous correlations among the disturbances. Their joint null is:

$$
H_{0}: \sum_{j=1}^{k} \rho_{i j}-1=0, \quad \forall i=1, \ldots, N
$$

and is tested by way of a Wald statistic.

The $\rho$ coefficients are allowed to differ across the panel members and the test also permits heterogeneous lags.

\footnotetext{
${ }^{7}$ A first application of the test appeared in 1997 as a CEPR Discussion Paper that was finally published as Taylor and Sarno (1999).

${ }^{8}$ Abuaf and Jorion (1990) also proposed a pooled multivariate unit root test of the DF type.
} 
Process (3) can also be specified in differences:

$$
\Delta d y_{i t}=\mu_{i}+\rho_{i} d y_{i t-1}+\sum_{j=1}^{k} \delta_{i j} \Delta d y_{i t-j}+u_{i t} \quad t=1, \ldots, T ; i=1, \ldots, N
$$

when the $M A D F$ test becomes a joint test of the null $\rho_{1}=\rho_{2}=\ldots=\rho_{N}=0$.

\section{Breuer et al. (2002) multivariate test.}

In the previous test, rejection of the null means that not all the members of the panel contain a unit root. Breuer et al. (2002) point out that there may be a mixture of $I(0)$ and $I(1)$ processes in the panel. However, as the tests are joint tests, rejection does not provide information about how many panel members follow the null, being impossible to identify which are the stationary and non-stationary crosssections. The second stage of the FPS test above and the Breuer et al. (2002) test proposed here can, on the contrary, identify which variables contain a unit root and which do not. Thus, they should be applied in the analysis once the null hypothesis of non-convergence has been rejected.

Breuer et al. (2002), also allow for heterogeneous serial correlation across the panel, contemporaneous correlation among the errors, and different autoregressive parameters for each panel member under the alternative. In contrast to the $M A D F$ test, separate null and alternative hypotheses are tested for each panel member within a SURE framework.

Similarly to the other tests, the SURADF test has nonstandard distributions and the critical values must be obtained by simulation. The simulation produces critical values for testing the null hypothesis that $\rho_{i}=0$, in an equation such as (5) for each individual member of the panel. The critical values, as in the FPS case, are specific to the estimated covariance matrix for the system considered and the sample size and number of panel members. The procedure allows identification of how many and which members of the panel contain a unit root.

\section{Empirical Results: Output Convergence in Mercosur Countries}

The data sample used in this paper covers the period 1960-1999. It has been obtained from the World Bank and consists of the logarithm of real GDP per capita in constant dollars (international prices, base year 1985) for Argentina, Bolivia, 
Brasil, Chile, Paraguay, Uruguay, and, finally, Peru as a control country. The original source is Penn World Table 5.6. and the missing data are calculated from 1985 GDP per capita and GDP per capita growth rates (Global Development Finance and World Development Indicators). In order to minimise the consequences of instability inherent to many Southern Cone countries, we stopped the series at 1999, to avoid introducing a few terminal points highly influenced by the Argentinean crisis?

Though economic integration between Argentina, Brazil and Uruguay started during the middle 80's, on a bilateral basis, Mercosur was formally created in 1991, after the Asunción Treaty was signed. Initially a free trade zone between Argentina, Brazil, Paraguay and Uruguay, Mercosur became an imperfect customs union in 1995. Indeed, on January 1st 1995, most tariff and many non-tariff barriers among the members had already been eliminated, and a common external tariff was set. Schedules for full implementation of the customs union had 2001 for its first target, but for Paraguay, that had to converge to the common external tariff by 2006. Recent local crises have delayed these deadlines.

In 1996, Chile and Bolivia were incorporated as associated members, i.e., they negotiate bilaterally with Mercosur. These negotiations aimed at their full participation at least in the free trade zone by 2006 .

In a preliminary analysis, we have implemented the traditional measures of $\sigma$ and $\beta$-convergence ${ }^{10}$. These results show that during the sixties and the seventies a steady convergence process occurred in the area, but this tendency was reverted at the beginning of the eighties. Although the dispersion in per-capita income in the whole Southern Cone area seems to have increased since then, this tendency has not been so acute in the Mercosur countries. The process of regional integration may explain the better performance of this group of countries and demands deeper attention from an empirical point of view.

In this section we present the empirical evidence obtained from three multivariate testing procedures applied to the Mercosur countries and associates. Brazil and Argentina, the two largest economies of the area, are used as benchmarks.

\footnotetext{
${ }^{9}$ The inclusion of the last group of time series information in the panel may decrease the power of the panel statistics if the variables have been subject to structural changes.

${ }^{10}$ These results, together with other alternative tests based on Bernard and Durlauf (1996) and Hobijn and Frances (2000) approaches, are available from the authors upon request.
} 


\section{A. Multivariate unit root tests I: no identification of countries outside the club}

In order to test for the null hypothesis of non-convergence among the different groups of countries (or clubs) considered, we apply two tests. First, Flôres et al. (1999) have proposed a unit root test in SURE regressions which allow for different autoregressive coefficients that has been already described. Here we present a version of this test, which includes an intercept ${ }^{11}$. Using a Wald test, the null $\rho_{1}=\rho_{2}=\ldots=\rho_{N}=1$, is tested in a model that includes a constant and the critical values are computed using Monte Carlo simulation. It should be stressed that the inclusion of the intercept implies that the concept of convergence that we are testing is that of catching-up. The reason for this choice is that for this group of countries the concept of long-run convergence would be too strict. Rejection of the null will, therefore, imply that some degree of on going convergence may exist among the countries analyzed.

In Table 2 and taking Brazil as the first benchmark country, the null hypothesis is rejected for the club including the Mercosur countries and Bolivia, as well as in the club that includes the whole group of countries. Non-convergence cannot be rejected, however, for the club formed by Mercosur and Chile ${ }^{12}$. When the benchmark is Argentina, the null is rejected in the two clubs considered.

The second test was proposed by Sarno and Taylor (1998) and was described in the previous section. In contrast to the Flôres et al. (1999) test, that was a multivariate version of the DF test, they introduce higher orders of autocorrelation.

Table 2. First stage of the Flôres et al. (1999) test

\begin{tabular}{llcccc}
\hline Benchmark & \multicolumn{1}{c}{ Club } & Wald DF & $99 \%$ crit. & $95 \%$ & $90 \%$ \\
\hline Brazil & Arg, Bol, Par, Ur & $18.922^{* * *}$ & 16.160 & 12.148 & 10.606 \\
Brazil & Arg, Ch, Par, Ur & 12.851 & 19.407 & 14.952 & 13.047 \\
Brazil & Arg, Bol, Ch,Par, Pe, Ur & $25.169^{* *}$ & 25.990 & 20.769 & 17.795 \\
Argentina & Bo, Br, Ch, Par, Pe, Ur & $25.154^{* * *}$ & 24.432 & 19.845 & 17.478 \\
Argentina & Bo, Br, Par, Ur & $19.543^{* * *}$ & 16.300 & 12.344 & 10.312 \\
\hline
\end{tabular}

Note: The asterisks $(*),(* *)$ and $(* * *)$ denote rejection of the hypothesis of no convergence (nonstationarity) at 10,5 and $1 \%$ respectively.

\footnotetext{
${ }^{11}$ Flôres et al. (1999) show that the results still hold when an intercept is included in the estimation, whether or not it exists in the data generating process. The presence of the intercept will allow for stationarity around a non-zero mean, that is, a less restricted version of convergence.

${ }^{12}$ For both, Brazil and Argentina, we have considered, as the main reference, the whole group of countries in the sample. Then, we have tried different combinations. We present here the main results.
} 
Table 3. Sarno and Taylor MADF test (1998)

\begin{tabular}{llcccc}
\hline \multicolumn{1}{c}{ Benchmark } & \multicolumn{1}{c}{ Club } & MADF & $99 \%$ crit. & $95 \%$ & $90 \%$ \\
\hline Brazil & Arg, Bol, Par, Ur & $18.07^{* *}$ & 21.06 & 16.07 & 13.45 \\
Brazil & Arg, Ch, Par, Ur & $16.48^{*}$ & 22.60 & 16.85 & 14.11 \\
Brazil & Arg,Bo,Ch,Par,Pe,Ur & $26.89^{* *}$ & 28.22 & 23.11 & 19.98 \\
Argentina & Bo, Br, Ch, Par, Pe, Ur & $25.47^{* * *}$ & 24.95 & 20.49 & 17.88 \\
Argentina & Bo,Br,Par,Ur & $22.33^{* * *}$ & 12.11 & 8.58 & 7.11 \\
\hline
\end{tabular}

Note: The asterisks $(*),(* *)$ and $(* * *)$ denote rejection of the hypothesis of no convergence (nonstationarity) at 10,5 and $1 \%$ respectively.

The MADF test is a joint test of the null $\rho_{1}=\rho_{2}=\ldots=\rho_{N}=0$. Also in this case, rejection of the null implies that not all the members of the panel contain a unit root.

The results of applying this test to the selected country groups are presented in table 3. Three of the groups have as benchmark country Brazil, whereas Argentina is the reference country in two other cases. Taking into account the variablesspecific critical values, it is possible to reject the null for all the country groups, what gives evidence in favor of, at least, partial convergence. In order to identify the countries that converge, we have applied the tests presented below.

\section{B. Multivariate unit root tests II: identifying countries outside the club}

To apply the second stage of the Flôres et al. (1999) test, we perform the unconstrained estimation of the system. We present in the first row of table 4 the results for the group of countries formed by Mercosur plus Bolivia, with Brazil as the benchmark country. Using the residuals, we proceed to compute 10.000 simulations where some series are taken to be stationary. In this case, we assume that the stationary series are the ones of Paraguay and Uruguay. The critical values obtained from these simulations for Argentina and Bolivia do not allow the rejection of the unit root hypothesis in the first case, although for Bolivia the nonstationarity can be rejected at 5 per cent.

In the second group, formed by Mercosur plus Chile, we take again as the stationary variables that of Paraguay and Uruguay. The results are more discouraging than in the former case: it is not possible to reject the null of nonstationarity in either case, Argentina or Chile.

Finally, in the group including all the countries with Brazil as the benchmark, the only converging countries are Paraguay and Uruguay.

A similar exercise has been performed having Argentina as the leader. In the 
Table 4. Flôres et al. (1999) unit root test

\begin{tabular}{cccccc}
\hline Benchmark & Club & $\beta$ & $10 \%$ & $5 \%$ & $1 \%$ \\
\hline Brazil & Arg. & 0.9403 & 0.8929 & 0.8493 & 0.7337 \\
& Bol. & $0.9615^{* *}$ & 0.9736 & 0.9666 & 0.9514 \\
& Par. & $0.8209^{* * *}$ & --- & --- & --- \\
Brazil & Ur. & $0.8709^{* * *}$ & --- & --- & --- \\
& Arg. & 0.9398 & 0.8882 & 0.8433 & 0.7348 \\
& Bol. & 0.9742 & 0.9640 & 0.9515 & 0.9169 \\
& Chile & 0.9169 & 0.8395 & 0.7932 & 0.6888 \\
& Par. & $0.8092^{* * *}$ & --- & --- & --- \\
Argentina & Peru & 0.9561 & 0.9126 & 0.8778 & 0.7799 \\
& Ur. & $0.8649^{* * *}$ & --- & --- & --- \\
& Bol. & $0.7388^{* * *}$ & --- & --- & --- \\
& Br. & 0.9359 & 0.9291 & 0.8951 & 0.8122 \\
& Chile & 1.0187 & 0.8842 & 0.8430 & 0.7477 \\
& Par. & $0.9180^{* * *}$ & 0.9874 & 0.9841 & 0.9777 \\
& Peru & $0.8125^{* * *}$ & --- & --- & --- \\
& Ur. & 0.9681 & 0.8460 & 0.8031 & 0.7017 \\
& Bol. & $0.6999^{* * * *}$ & --- & --- & --- \\
& Br. & $0.9111^{* * *}$ & 0.9628 & 0.9512 & 0.9221 \\
& Par. & $0.9016^{* * *}$ & 0.9874 & 0.9845 & 0.9789 \\
& Ur. & 0.9632 & 0.8394 & 0.7938 & 0.6825 \\
\hline
\end{tabular}

Note: The asterisks $(*),(* *)$ and $(* * *)$ denote rejection of the hypothesis of no convergence (nonstationarity) at 10,5 and $1 \%$ respectively.

large group, Bolivia, Paraguay and Peru converge, whereas for the case of Mercosur plus Bolivia, the converging countries are Bolivia, Brazil and Paraguay.

These results are partially confirmed by those obtained using the Breuer et al. (2002) test. In the two groups of countries above mentioned, Paraguay and Uruguay converge towards Brazil, whereas the rest of countries do not. A larger club (Mercosur plus Bolivia, Chile and Peru) does not change significantly the outcome: Peru is also added to the countries converging with Brazil.

An equivalent group has been also defined in relation to Argentina. The evidence is less strong, although some convergence is found between Argentina and all the country-group, with the exception of Chile and Uruguay. The clearest rejection of non-convergence appears in relation to Bolivia. In a second step, we have excluded the no converging countries from the group and obtain more clear rejections, with the exception of Brazil (at 10 per cent).

The comparison of the results obtained with the two benchmark countries indicates that, in general, the small countries (namely Bolivia, Paraguay, Peru and 
Table 5. Breuer et al. (2002) SURADF test

\begin{tabular}{|c|c|c|c|c|c|}
\hline Benchmark & Club & SURADF & $10 \%$ & $5 \%$ & $1 \%$ \\
\hline \multirow[t]{4}{*}{ Brazil } & Arg. & -1.5139 & -2.6078 & -2.9567 & -3.5321 \\
\hline & Bol. & -1.1295 & -2.6071 & -2.8799 & -3.3770 \\
\hline & Par. & $-2.8620^{* * *}$ & -1.4187 & -1.7661 & -2.5482 \\
\hline & Ur. & $-3.8242^{* * *}$ & -1.5639 & -1.9694 & -2.6121 \\
\hline \multirow[t]{4}{*}{ Brazil } & Arg. & -1.3347 & -2.6483 & -2.9613 & -3.4259 \\
\hline & Chile & -2.1436 & -2.6204 & -3.0250 & -3.6580 \\
\hline & Par. & $-2.6093^{* * *}$ & -1.4279 & -1.8076 & -2.5175 \\
\hline & Ur. & $-3.5516^{* * *}$ & -1.7079 & -2.1718 & -3.0107 \\
\hline \multirow[t]{6}{*}{ Brazil } & Arg. & -1.5426 & -2.6388 & -2.9446 & -3.6944 \\
\hline & Bol. & -0.9288 & -2.8399 & -3.1177 & -3.8831 \\
\hline & Chile & -2.4687 & -2.8802 & -3.1977 & -3.6871 \\
\hline & Par. & $-2.8731^{* * *}$ & -1.4613 & -1.8143 & -2.6380 \\
\hline & $\mathrm{Pe}$ & $-2.8627^{* * *}$ & -1.4579 & -1.8416 & -2.7360 \\
\hline & Ur. & $-3.9108^{* * *}$ & -1.7357 & -2.1138 & -2.8014 \\
\hline \multirow[t]{6}{*}{ Argentina } & Bol. & $-4.2116^{* * *}$ & -1.4918 & -2.0026 & -2.5366 \\
\hline & Br. & $-2.6852^{*}$ & -2.4203 & -2.7576 & -3.3863 \\
\hline & Chile & -0.1101 & -2.7289 & -2.0587 & -3.6127 \\
\hline & Par. & $-1.9066^{*}$ & -1.6024 & -1.9827 & -2.7592 \\
\hline & Per. & $-1.6859^{*}$ & -1.4960 & -1.8334 & -2.6286 \\
\hline & Ur. & -1.1353 & -2.7873 & -3.0745 & -3.6038 \\
\hline \multirow[t]{4}{*}{ Argentina } & Bol. & $-3.9095^{* * *}$ & -1.2735 & -1.6804 & -2.4260 \\
\hline & $\mathrm{Br}$. & $-2.4402^{*}$ & -2.2765 & -2.6010 & -3.1357 \\
\hline & Par. & $-1.3310^{* * *}$ & -0.7734 & -0.9155 & -1.1190 \\
\hline & Ur. & $-1.9250^{* *}$ & -1.2542 & -1.5442 & -2.1332 \\
\hline
\end{tabular}

Note: The asterisks $(*),(* *)$ and $(* * *)$ denote rejection of the hypothesis of no convergence (nonstationarity) at 10,5 and $1 \%$ respectively.

Uruguay) are converging towards the two larger countries (Argentina and Brazil), whereas the evidence of convergence between the two large economies is very weak. Concerning Chile, this country does not converge with any of the two large neighbors, confirming its relative isolation from the rest of the area, probably due to the different macroeconomic policies applied.

Finally, in Table 6 we compare the results of the two tests that identify the converging countries applied in this section. The results for Argentina are identical: Bolivia, Brazil, Paraguay and Peru would be catching up with Argentina, whereas for the case of Brazil, the two tests support that Paraguay and Uruguay would be catching up with Brazil. In addition, the FPS test finds convergence with Bolivia, whereas the SURADF test identifies Peru as the third converging country. 
Table 6. Summary of convergence results from the multivariate tests that identify the converging countries

\begin{tabular}{ccc}
\hline Countries & FPS test & SURADF test \\
\hline Bra-Arg & --- & --- \\
Bra-Bol & Yes & --- \\
Bra-Chi & --- & --- \\
Bra-Par & Yes & Yes \\
Bra-Pe & --- & Yes \\
Bra-Ur & Yes & Yes \\
Arg-Bol & Yes & Yes \\
Arg-Bra & Yes & Yes \\
Arg-Chi & --- & --- \\
Arg-Par & Yes & Yes \\
Arg-Pe & Yes & Yes \\
Arg-Ur & --- & --- \\
\hline
\end{tabular}

Note: The word "Yes" indicates evidence in favor of convergence.

\section{The European Union experience: some policy implications for Mercosur}

Much of the research on per capita income convergence has focused on developed countries or regions. However, studies of convergence in developing countries have tended to concentrate on within country convergence. Moreover, the fact that many countries are involved in regional integration processes as well as in a multilateral liberalization process, makes more difficult to disentangle the different effects derived from economic integration. There is no doubt that the best known case study to use as a benchmark is the performance achieved by the European Union (EU). For the last 50 years there has been widespread discussion about the economic consequences of EU. The creation of the EU as a trade bloc was based on the idea that its existence would guarantee increased growth and welfare to all its member countries. However, it is not clear that these beneficial effects were geographically evenly distributed. As we have already mentioned in section 1, there exist two strands of economic literature, based on very different growth models and international trade theories, which give rise to two opposite outcomes.

The empirical studies ${ }^{13}$ show that while the dispersion of income levels across countries is still very high, the gaps among EU members have been steadily narrowing (i. e. standard deviation of national incomes per capita fell by 4.4 points from 1983 to 1993 and has continuously been dropping up to present. This catching-up process has been particularly important in the so-called "cohesion 
countries", namely Greece, Ireland, Spain and Portugal. The convergence across nations, however, hides a controversial fact: income inequality across regions within the EU nations has been rising steadily. There is a spread agreement in the empirical literature signalling that EU membership has had a positive and asymmetric effect on long term growth. The results would imply that the relatively less developed countries profit most from access to the broader technological framework offered by the regionally integrated unit.

However, one could argue that technology is not the only factor explaining the growth bonus associated with EU membership and that the convergence results obtained depend greatly on the financial help from the EU to the relatively poorer members. One fact that makes the EU experience quite unique among other regional integration processes is its high level of financial solidarity. European authorities took for granted from the beginning that market forces alone would not solve the regional inequalities and the decision was taken at a European level to help the less developed regions in their efforts. In fact, the European regional policy gained renewed impetus each time an enlargement took place and new geographical economic inequalities appeared. Correspondingly, the amount of funds devoted to regional policy also increased. Similar provisions do not appear in any other regional economic integration processes. This fact makes very difficult to compare performances in income convergence across member countries in the EU and other blocs, like Mercosur.

Since its creation, Mercosur has suffered from recurrent trade tensions among its members, caused by divergent macroeconomic developments and sharp fluctuations in their real exchange rates. During the 1980s there was a considerable increase in foreign transfers as a result of high interest rates and reduced external financing. However, internal constraints and macroeconomic imbalances exacerbated the problems and it became difficult to manage economic policies. In order to solve this problem, Mercosur launched, in 2000, an initiative to foster coordination of the macroeconomic policies: the Macroeconomic Monitoring Group (MMG). From September 2000, the member countries started publishing harmonized indicators for fiscal deficit, debt and inflation.

However, a little later, Argentina entered in a great crisis, experiencing currency devaluation, sovereign debt default and a freeze on bank accounts, after ten years

\footnotetext{
${ }^{13}$ See, for instance, Barro and Sala-i-Martin (1991), Sala-i-Martin (1996), Armstrong (1995), Neven and Gouyette (1995), Canova and Marcet (1995), Lee, Pesaran and Smith (1997), Crespo-Cuaresma et al (2002).
} 
of one-to-one parity with the US dollar. Argentina did not attend any of the two meetings the MMG held in 2001, the year the crisis exploded. After an extremely hard 2002, prospects have improved and a new Argentinean government, elected in 2003, is again supportive of Mercosur's monetary integration. Indeed, once Argentina decided to abandon its currency board agreement in January 2002, the interest in monetary integration with Mercosur was reinforced as a way of establishing a credible monetary regime. At the same time, Brazil seems to be interested in re-launching the process of regional integration as an alternative to the continental one led by the US. Under this framework, the assessment of real convergence becomes a key factor for future decisions. The empirical results obtained in this paper suggest the need for pro-active policies in order to promote growth and reduce income inequalities.

The $28^{\text {th }}$ Mercosur Summit held in Paraguay in June 2005 has confirmed the importance of real convergence with the creation of a cohesion fund, called FOCEM. This fund, similar to its European equivalent, is aimed at promoting competitiveness, social cohesion, structural convergence and to reinforce economic integration in the area. Brazil and Argentina are the main contributors whereas Paraguay and Uruguay will receive the majority of the resources. In addition, Mercosur members seem to lack further synchronization in their business cycles that only could reached by deepening real integration (including, at least, trade in goods and services and foreign direct investment).

\section{Summary and Concluding Remarks}

In this paper we have used multivariate tests in order to assess the degree of per capita income convergence in Mercosur and associate countries. The approach taken combines the applicability of well-defined testable hypotheses from the time series literature on convergence with recent multivariate techniques that allow for cross-country effects. This approach has two main advantages: first, to account for these relations is a basic feature in economic integration analysis, as it adds relevant information contained in the dataset that, otherwise, would be ignored; second, by adding the cross-section dimension, the use of this information can help us to avoid two econometric problems. First, the bias towards the non rejection of the hypothesis of non-convergence derived from the lack of power of unit root tests in small samples. Secondly, the capacity to use a relatively short sample allow us to avoid size problems in the unit root tests connected to possible discontinuities in the 
series.

We are assuming that Mercosur countries have not achieved long-run convergence yet but that the integration process can be fostering a catching-up process. Using as benchmark countries Brazil and Argentina, we have applied multivariate unit root tests. The use of multivariate SURE unit root tests implies a step forward in the study of per capita income convergence. Two possibilities are considered that are complementary and can be viewed as part of the testing strategy. First, the MADF test and the first stage of the FPS test impose the same alternative hypothesis for all the cross-sections, so that there is no precise identification of the countries that are outside the convergence club. Then, the second stage of FPS and the SURADF test are applied to the individual countries separately and are able to identify those that are converging (or catching-up). Although different in their formulation, the countries that catch-up according to the FPS and the SURADF tests are practically the same, which adds robustness to the analysis.

To summarize the empirical results that we have obtained, we can outline the following conclusions. First, although partial, there is consistent evidence on convergence in the form of catching-up among the countries participating in Mercosur, as well as with the associate and neighbors countries. Second, due to the particular configuration of the area, there are two large countries, which may be used as benchmark for the analysis, whereas the rest (with the possible exception of Chile) are small economies. The evidence found points to catching-up of the small countries towards the large ones. There is weaker evidence of catching-up between Argentina and Brazil, as well as with each of these two countries and Chile. Finally, if we consider separately the countries that are Mercosur members and the associates and Peru, the evidence suggests that the process of convergence has been stronger for those in Mercosur.

Overall, although the regional integration process seems to have fostered income convergence among Mercosur member countries, there seems to be a strong case for strengthening regional integration via an ever closer macroeconomic coordination and a pro-active regional policy, following the European Union example.

\section{Acknowledgments}

The authors gratefully acknowledge the financial support from the AECI, as 
well as from the CICYT and Feder project SEJ2005-01163 and the Generalitat Valenciana project ACOMP07/102. They are also indebted to Leonardo Souza that wrote the Matlab programme to compute the Flôres et al. (1996) tests, as well as to J. B. Breuer, R. McNown and M. Wallace for their RATS procedure to compute Taylor and Sarno (1999) and their own test. Mariam Camarero and Cecilio Tamarit are members of the research group on Economic Integration (INTECO).

Received 25 June 2006, Accepted 17 October 2007

\section{References}

Abuaf, N. and P. Jorion (1990): "Purchasing Power Parity in the Long Run"', Journal of Finance, vol. XLV, n. 1, 157-174.

Armstrong, H.W. (1995): "Convergence among regions of the European Union 19501990", Paper in Regional Science, 74, 143-152.

Barro, R.J. (1991): “Economic growth in a cross-section of countries", Quarterly Journal of Economics, vol. 106, 407-443.

Barro; R. J. and X. Sala-i-Martin (1991): "Convergence across states and regions", Brookings Papers on Economic Activity, 107-158.

Baumol, W.J. (1986): Productivity growth, convergence, and welfare: what the long-run data show, American Economic Review, vol. 76, 1072-85.

Baumol, W.J. (1994): Multivariate growth patterns: Contagion and common forces as possible sources of convergence, chapter 3, 62-85, in Baumol, W.J., R.R. Nelson and E.N. Wolff (eds.) Convergence of Productivity. Cross-national studies and historical evidence, Oxford University Press.

Baumol, W.J., R.R. Nelson and E.N. Wolff (1994): Introduction: The Convergence of Productivity, Its Significance, and Its Varied Connotations, 1-19, in Baumol, W.J., R.R. Nelson and E.N. Wolff (eds.) Convergence of Productivity. Cross-national studies and historical evidence, Oxford University Press.

Ben-David, D. (1994): Convergence clubs and diverging economies, CEPR Discussion Paper, n. 922.

Ben-David, D. (1996): Trade and convergence among countries, Journal of International Economics, vol. 40, 279-298.

Bernard, A.B. and S.N. Durlauf (1995): "Convergence in international output", Journal of Applied Econometrics, vol. 10, 97-108.

Bernard, A.B. and S.N. Durlauf (1996): Interpreting tests of the convergence hypothesis, Journal of Econometrics, vol. 71, 161-173.

Bowman, K. and Felipe, J. (2001): Economic convergence and trade integration in Latin America, 2001 Annual Meeting of the Political Science Association, San Francisco.

Breuer, J.B., R. McNown and M. Wallace (2002): Series-specific Tests for a Unit Root in 
a Panel Setting with an Application to Real Exchange Rates, Oxford Bulletin of Economics and Statistics, 64, 5:527-546.

Cáceres, L.R. and Sandoval, O.N. (1999): Crecimiento económico y divergencia en América Latina, El Trimestre Económico, n. 264, 781-796.

Cheung, Y-W and A. García-Pascual (2004): "Testing for output convergence: a reexamination", Oxford Economic Papers 56, 45-63.

Crespo-Cuaresma, J., Dimitz, M. A. and D. Ritzbeger-Grünwald (2002): Growth, Convergence and EU membership, ONB Working Paper 62.

DeLong, J.B. (1988): Productivity growth, convergence, and welfare: Comment, American Economic Review, vol. 78, 1138-54.

Dobson, S. Ramlogan (2002): Economic growth and convergence in Latin America, The Journal of Development Studies, vol. 38, n. 6, 83-104.

Flôres, R., P. Jorion, P.Y. Preumont, and A. Szafarz (1999): Multivariate unit root tests of the PPP hypothesis, Journal of Empirical Finance, vol. 6, 335-353.

Greasley, D. and Oxley, L. (1997): "Time-series based tests of the convergence hypothesis: Some positive results", Economics Letters, 56: 143-147.

Hadri, K. (2000). "Testing for stationarity in heterogeneous panel data", Econometrics Journal, vol. 3, n. 2, pp. 148-161.

Hobijn, B. and P.H. Franses (2000): "Asymptotically perfect and relative convergence of productivity", Journal of Applied Econometrics, vol. 15, n.1, 59-82.

Im, K., M.H. Pesaran and Y. Shin (2003): "Testing for unit roots in heterogeneous panels", Journal of Econometrics, vol. 115, 53-74.

Johansen, S. (1988): "Statistical analysis of cointegration vectors", Journal of Economic Dynamics and Control, vol. 12, 231-54.

Krugman, P., (1991): “Increasing Returns and Economic Geography," Journal of Political Economy, vol. 99(3), pages 483-99.

Lee, K., Pesaran, M. H. and R. Smith (1997): "Growth and convergence in a multicountry empirical stochastic Solow model", Journal of Applied Econometrics 12, 357-392.

Levin, A., C. Lin and C. Chu (2002): "Unit root tests in panel data: Asymptotic and finitesample properties", Journal of Econometrics, vol. 108, 1-24.

Mankiw, N.G., D. Romer and D.N. Weil (1992): "A contribution to the empirics of economic growht, Quarterly Journal of Economics, vol. 107, 407-437.

Maddala, G. S. and S. Wu (1999). A Comparative Study of Unit Root Tests with Panel Data and a New Simple Test, Oxford Bulletin of Economics and Statistics, Special Issue, 61, 631-652.

Neven, D. and C. Gouyette (1995): "Regional convergence in the European Community", Journal of Common Markent Studies 33, 47-65.

O'Connell, P. G. J. (1998). The overvaluation of the purchasing power parity, Journal of International Economics, 44, 1-19.

Oxley, L. and Greasley, D. (1995): A Time-Series Perspective on Convergence: Australia, UK and USA since 1870, The Economic Record 71: 259-270. 
Phillips, P.C.B. and S. Ouliaris (1988): "Testing for cointegration using principal components methods", Journal of Economic Dynamics and Control, vol. 12, 205-230.

Quah, D. (1990): International patterns of growth: Persistence in cross-country disparities, mimeo, MIT.

Quah, D. (1996a): Convergence empirics across countries with (some) capital mobility, Journal of Economic Growth, vol. 1, 95-124.

Quah, D. (1996b): "Twin peaks: Growth and convergence in models of distribution dynamics", The Economic Journal, vol. 106, 1045-1055.

Reichlin, L. (1999): "Discussion" to D. Quah, "Convergence as distribution dynamics (with or without growth)" in R. Baldwin, D. Cohen, A. Sapir and A. Venables, Market integration, regionalism and the global economy, CEPR, Cambridge, Cambridge University Press.

Romer, P. (1986): Increasing returns and long-run growth, Journal of Political Economy vol. 94, 1002-37.

Sala-i-Martín, X. (1990): "On growth and states”, Ph.D. dissertation, Harvard University.

Sala-i-Martín, X. (1996a): "The classic approach approach to convergence analysis", the Economic Journal, vol. 106, 1019-1036.

Sala-i-Martín, X. (1996b): "Regional cohesion: Evidence and theories of regional growth and convergence", European Economic Review 40, 1325-1352.

Sarno, L. and M. Taylor (1998): "Real exchange rates under the recent float: unequivocal evidence of mean reversion", Economics Letters, vol. 60, 131-137.

Serra, M.I., M.F. Pazmino, G. Lindow, B. Sutton and G. Ramírez (2006): "Regional convergence in Latin America", IMF Working Paper WP/06/125, Washington.

Slaughter, M.J. (2001): Trade liberalization and per capita income convergence: a difference-in differences analysis, Journal of International Economics, vol. 55, 203-228.

Solow, R.M. (1956): A contribution to the theory of economic growth, Quarterly Journal of Economics, vol. 70, 65-94.

Summers, R. and A. Heston (1991): "Penn World Table (Mark 5): An expanded set of international comparisons, 1955-1988", Quarterly Journal of Economics, vol. 106, 327-368.

Sarno, L. and M. Taylor (1998): "Real exchange rates under the recent float: unequivocal evidence of mean reversion", Economics Letters, vol. 60, 131-137.

Shiller, R. J. and P. Perron (1985): "Testing the random walk hypothesis: power versus frecuency of observation", Economics Letters, vol. 18, 4, 381-386.

Taylor, M. and L. Sarno (1999): The behavior of real exchange rates during the postBretton Woods period, Journal of International Economics vol. 46, 281-312.

Volpe Martincus, C. (2000): Integración económica y localización de la actividad productiva: el caso del MERCOSUR, Documento de Trabajo 23, Departamento de Economía, Universidad de la Plata. 